\title{
Extracellular signal-regulated kinase and Akt activation play a critical role in the process of hepatocyte growth factor-induced epithelial-mesenchymal transition
}

\author{
TOSHIYUKI TANAHASHI, SHINJI OSADA, ATSUKO YAMADA, JUNKO KATO, KAZUNORI YAWATA, \\ RYUTARO MORI, HISASHI IMAI, YOSHIYUKI SASAKI, SHIRO SAITO, YOSHIHIRO TANAKA, \\ KENICHI NONAKA and KAZUHIRO YOSHIDA
}

Department of Surgical Oncology, Gifu University Graduate School of Medicine, Gifu, Japan

Received September 25, 2012; Accepted November 12, 2012

DOI: 10.3892/ijo.2012.1726

\begin{abstract}
Epithelial-mesenchymal transition (EMT) has recently been studied to elucidate mechanisms of the liver metastatic process. We investigated EMT in the process of liver metastasis and the effects of chemotherapy on EMT cells as therapeutic strategy for colorectal liver metastasis. We used the CT26 murine colorectal carcinoma cell line to create an in vivo mouse liver metastasis model. Liver tumors were stained immunohistochemically. Expression of proteins associated with TGF- $\beta /$ Smad and hepatocyte growth factor (HGF)/c-Met pathways were investigated by western blotting. Cells with c-Met mRNA knockdown by siRNA techniques showed clearly reduced liver metastases compared with regular cells at 21 days. TGF- $\beta$ and HGF induced EMT expression, but signal transduction was quite different. TGF- $\beta$ induced ERK, but not Akt phosphorylation. HGF mediated both ERK and Akt phosphorylation. Akt inhibitor blocked Akt phosphorylation but did not affect TGF- $\beta$-induced activation of ERK, Snail and Slug. U-0126 did not reduce Snail activity by TGF- $\beta$ at a concentration to block ERK phosphorylation. However, Akt inhibitor and U-0126 completely inhibited HGF-induced Slug activation. 5-FU mediated cell death in the EMT process induced by TGF- $\beta$ more effectively than HGF. ERK/Akt signaling, but not the Smad pathway, may be one of the main processes in HGF-induced EMT, despite the Smad pathway, but not ERK/ Akt, being critical for TGF- $\beta$-induced EMT. The MAPK/Akt pathway is indispensable in HGF/c-Met signaling. The ERK/ Akt pathway particularly may be critical in the HGF-induced EMT process. However, long-term use of chemotherapeutic agents may induce drug resistance and distant metastases through EMT-related signaling pathway activation.
\end{abstract}

Correspondence to: Dr Shinji Osada, Department of Surgical Oncology, Gifu University Graduate School of Medicine, 1-1 Yanagido, Gifu 501-1194, Japan

E-mail: sting@gifu-u.ac.jp

Key words: epithelial-mesenchymal transition, liver, metastasis, c-Met, hepatocyte growth factor, transforming growth factor- $\beta$, ERK/Akt pathway, 5-FU

\section{Introduction}

Colorectal cancer (CRC) is the third most common epithelial malignancy worldwide: approximately 1,000,000 new cases and 500,000 deaths occur each year (1). Liver metastases develop in 40-50\% of patients with CRC and represent one of the most common causes of death. Surgical resection remains an expected procedure to ensure long-term survival or cure (2). After hepatectomy to treat metastatic liver tumor, activation of the signaling pathway from c-Met-related hepatocyte growth factor (HGF) becomes important in the progress of liver regeneration. Because the HGF/c-Met pathway also plays a critical role in the carcinogenesis of CRC (3), an increased level of serum HGF following hepatectomy has been feared to prompt cancer growth. We previously reported that c-Met overexpression was closely associated with liver metastasis, but c-Met expression is reduced in liver metastatic lesions compared with that seen in primary lesions (4). Therefore, surgical resection might unfavorably affect cancer cell progression, but the mechanism and outcome of c-Met expression remain unclear.

During key biological processes such as embryonic development, tissue remodeling, restitution, or wound repair, epithelial cells must escape from their rigid structural constraints through a well-known process termed epithelial-mesenchymal transition (EMT) (5). As an inducer of EMT in normal mammary epithelial cells, transforming growth factor- $\beta$ (TGF- $\beta$ ) was first described and evaluated as a key factor (6). The TGF- $\beta$ family of polypeptides is associated with a wide variety of biological functions, and its effect is elicited through activation of $\mathrm{Smad} 2 / 3 / 4$ for translocation from receptor to the nucleus. In CRC cells, loss of TGF- $\beta$ sensitivity is frequently due to loss of or mutation in the signaling pathway, notably to its receptor and to the Smad process $(7,8)$. TGF- $\beta$ induces non-Smad pathways including those of mitogen-activated protein kinase (MAPK) or phosphoinositide 3-kinase (PI3K) (9). Substantial activation of the HGF/c-Met pathway also leads to scattering and invasion of cancer cells through activation of the cell signaling pathway, and it may regulate EMT (10).

The purpose of the present study was to further develop our previous study on c-Met expression in CRC (4), to investigate EMT in the process of liver metastases, and to evaluate the 
effects of chemotherapy on EMT cells as a therapeutic strategy for colorectal liver metastasis.

\section{Materials and methods}

Cell lines and culture conditions. Cells from the CT26 murine colorectal carcinoma cell line were obtained from the American Type Culture Collection (ATCC, Manassas, VA). Cells were cultured in RPMI-1640 medium (Wako, Osaka, Japan) supplemented with $10 \%$ heat-inactivated fetal bovine serum (FBS), $1 \mathrm{mM}$ HEPES buffer, $1 \mathrm{mM}$ sodium pyruvate solution, and $1 \%$ penicillin-streptomycin-amphotericin solution (all from Sigma-Aldrich, St. Louis, MO) in a humidified atmosphere of $5 \% \mathrm{CO}_{2} / 95 \%$ air at $37^{\circ} \mathrm{C}$. Cells were passaged twice a week.

Animals housing and in vivo experiments. Male 5-week-old BALB/c mice were purchased from SRL (Hamamatsu, Japan) and housed in the animal facilities of the Division of Animal Experiment, Life Science Research Center, Gifu University with free access to water and food. A liver metastatic model of CRC was created by injection of $1.0 \times 10^{6}$ CT26 cells into the spleen of BALB/c mice as described previously (4). At 21 days after injection, murine spleen and liver were removed and evaluated by western blot analysis, in an immunohistochemical study. Animal experiments in this study were performed in compliance with the guidelines of the Institute for Laboratory Animal Research, Gifu University Graduate School of Medicine, and the UCCCR Guidelines for the Welfare of Animals in Experimental Neoplasia.

Cell proliferation assay. Cell growth was assessed by a standard 3-(4,5-dimethyl-thiazol-2-yl)-2,5-dephenyltetrazolium bromide (MTT) assay $(11,12)$, which detects the dehydrogenase activity in viable cells. A total of $3 \times 10^{3}$ CT26 cells were seeded into each of the 96-well culture plates or the same density of cells was seeded in 6-cm dish plates overnight and kept in a humidified atmosphere of $5 \% \mathrm{CO}_{2}$ and $95 \%$ air at $37^{\circ} \mathrm{C}$. The medium was exchanged for serum-free RPMI-1640 medium, and after 48 -h incubation, growth stimulation by growth factors was started by adding $5 \mathrm{ng} / \mathrm{ml}$ of TGF- $\beta$ and 20 or $40 \mathrm{ng} / \mathrm{ml}$ of HGF to each well in the same condition. Recombinant TGF- $\beta 1$ and recombinant HGF were purchased from R\&D Systems (Minneapolis, MN). After $72 \mathrm{~h}$, the culture medium was removed, and $100 \mu \mathrm{l}$ of a $0.5-\mathrm{mg} / \mathrm{ml}$ solution of MTT (SigmaAldrich) was added to each well. The plates were then incubated for $4 \mathrm{~h}$ at $37^{\circ} \mathrm{C}$. The culture medium was replaced with $100 \mu \mathrm{l}$ of dimethyl sulfoxide (Wako) per well, and the absorbance at the 540-nm wavelength was measured using a 2104 EnVision Multilabel Reader (Perkin-Elmer, Waltham, MA).

In preparing the protein samples, cells were treated with Akt inhibitor (BioVision, Inc., Mountain View, CA), and U-0126 (Cayman Chemical, Ann Arbor, MI) for $24 \mathrm{~h}$ before administration of growth factors. 5-FU (Kyowa-Kirin, Tokyo, Japan) was administered after $96 \mathrm{~h}$ of contact with growth factors.

Western blot analysis and antibodies. Treatment of the specimens was as described previously (13-15). Cell lysates were boiled in Sample Buffer Solution (Wako). Total cell protein extracts $(20 \mu \mathrm{g} /$ lane $)$ were separated by sodium dodecyl sulfate-polyacrylamide gel electrophoresis using SuperSep ${ }^{\mathrm{TM}}$
(Wako) and were electrophoretically transfected onto polyvinyl difluoride membranes. The membranes were blocked with PVDF blocking reagent (Toyobo, Osaka, Japan) for $1 \mathrm{~h}$. The membranes were then incubated with primary antibodies against $\beta$-actin, E-cadherin, vimentin, Snail (Snail1), Slug (Snail2), Smad pathway proteins (p-Smad2, p-Smad3), p-ERK (extracellular signal-regulated kinase), ERK, p-Akt, Akt, p-JNK (c-jun N-terminal kinase), JNK, and caspase-3 (1:5,000; Cell Signaling Technology, Danvers, MA) overnight at $4^{\circ} \mathrm{C}$. The primary antibodies were diluted with Can Get Signal Solution 1 (Toyobo). The membranes were then washed with Dako Washing Buffer (Dako, Glostrup, Denmark) and incubated with the appropriate secondary antibodies (1:25,000; Millipore, Darmstadt, Germany), which were diluted with Can Get Signal Solution 2 (Toyobo). The immunoreactive proteins were visualized by chemiluminescence using ImmunoStar LD reagents (Wako), and images were captured by a LAS-4000 (Fuji film, Tokyo, Japan).

Immunohistochemistry. An LSAB kit (Dako) was used for immunohistochemical analysis $(16,17)$. In brief, sections were pretreated by microwave treatment in citrate buffer for 15 min to retrieve antigenicity. After peroxidase activity was blocked with $3 \% \mathrm{H}_{2} \mathrm{O}_{2} /$ methanol for $10 \mathrm{~min}$, sections were incubated with normal goat serum (Dako) for 20 min to block non-specific antibody binding sites. Sections were incubated with the following primary antibodies: c-Met, 1:200 dilution (Santa Cruz Biotechnology, Santa Cruz, CA) and E-cadherin, 1:100 dilution (Cell Signaling Technology). Sections were incubated with primary antibody for $1 \mathrm{~h}$ at $25^{\circ} \mathrm{C}$ followed by incubations with biotinylated anti-rabbit/mouse $\mathrm{IgG}$ and peroxidase-labelled streptavidin for $10 \mathrm{~min}$ each. Staining was completed by incubation for 10 min with substrate-chromogen solution. Sections were counterstained with $0.1 \%$ hematoxylin. No specific staining was observed in the negative control slides prepared without primary antibody.

Transfection and small interfering RNA experiments for $c$-Met . CT26 cells were cultured in a medium without antibiotics for $24 \mathrm{~h}$ before transfection to $50-70 \%$ confluence. Cells were transfected with a small interfering RNA (siRNA) oligonucleotide using Lipofectamine RNAiMAX (Invitrogen, Carlsbad, CA) in a final siRNA concentration of $40 \mathrm{nmol} / \mathrm{l}$ in serumfree Opti-MEM (Invitrogen) according to the manufacturer's instructions. At $6 \mathrm{~h}$ after transfection, the medium was replaced with RPMI-1640 medium supplemented with $10 \%$ FBS. The total proteins were extracted $48 \mathrm{~h}$ later, and expression levels of the c-Met protein were analyzed by western blotting. siRNA oligonucleotides for c-Met were purchased from Invitrogen.

Statistical analysis. The data were examined using the Student's t-test, $\chi^{2}$ test, and ANOVA or Kruskal-Wallis test (with appropriate post hoc analysis for multiple comparisons) to determine statistical significance. $p$-value of $<0.05$ was regarded as statistically significant.

\section{Results}

Effect of c-Met on cancer progression. HGF induced c-Met phosphorylation in the CT26 colorectal cancer cell line after 


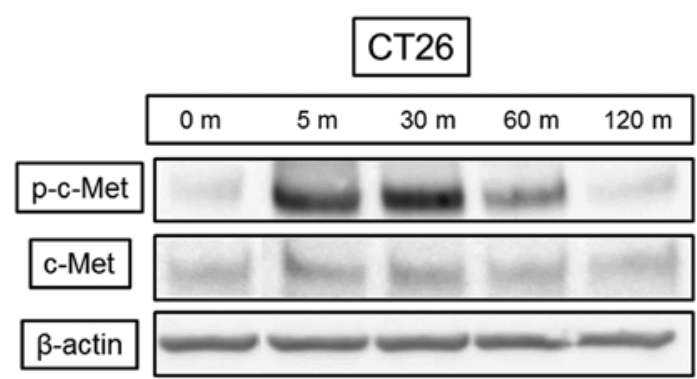

Figure 1. Effect of HGF on c-Met phosphorylation. HGF induced c-Met phosphorylation in the CT26 colorectal cancer cell line. Each band was obtained from western blotting as described in Materials and methods.

5 min with no change in the total amount of protein (Fig. 1). HGF at both the 20- and $40-\mathrm{ng} / \mathrm{ml}$ concentrations resulted in significant cell proliferation of $110 \%$ and $115 \%$, respectively, $(\mathrm{p}<0.05)$ compared with control at $72 \mathrm{~h}$ (data not shown).

Expression of c-Met was decreased with the increase of cell density, $39 \%$ on day 11 and $13 \%$ on day 14 , compared with day 7 , and E-cadherin expression was increased, $104 \%$ on day 11 and
139\% on day 14 (Fig. 2). Immunohistochemical study revealed the expression of both c-Met and E-cadherin to diminish in the metastatic liver tumors as shown in Fig. 3. Cells in which c-Met mRNA was knocked down by siRNA techniques (Fig. 4A) clearly showed reduced liver metastases compared with regular cells at day 21 in the in vivo BALB/c mouse model (Fig. 4B).

Signal pathway to EMT by TGF- $\beta$ and HGF. We compared the expression of E-cadherin and vimentin by HGF or TGF- $\beta$ (Fig. 5). The 20-ng/ml concentration of HGF reduced the level of E-cadherin as well as the 5-ng/ml concentration of TGF- $\beta$ in a time-dependent manner (TGF- $\beta$ decreased to $47.3 \%$ and HGF decreased to $60.8 \%$ at $96 \mathrm{~h}$ ), but knockdown of c-Met diminished the decrease of E-cadherin by HGF. HGF increased the expression of vimentin similarly to TGF- $\beta$ in a time-dependent manner (increased to $308 \%$ by TGF- $\beta$ and $221 \%$ by HGF at $96 \mathrm{~h})$. Next, we observed activation of EMT transcription factors (Fig. 6). Expression of Snail was detected with the addition of TGF- $\beta$ starting at $24 \mathrm{~h}$; it peaked at $48 \mathrm{~h}$ and remained peaked continuously to $96 \mathrm{~h}$. However, expression of Snail was not detected at any time after the addition of HGF. Slug expression was increased at $24 \mathrm{~h}$ by the addition of both TGF- $\beta$ and HGF.

A

\section{Day $7 \quad$ Day $11 \quad$ Day 14}

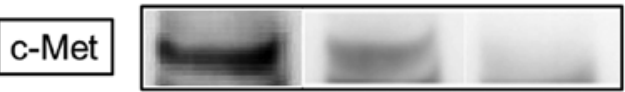

$\beta$-actin

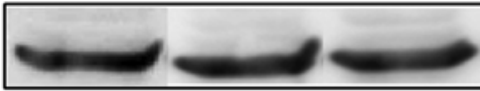

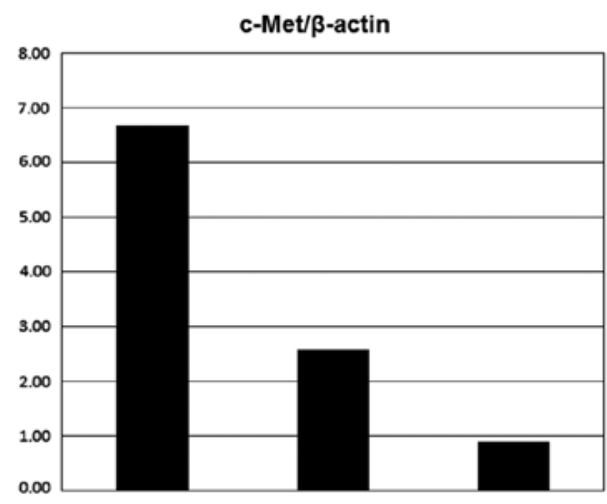

B

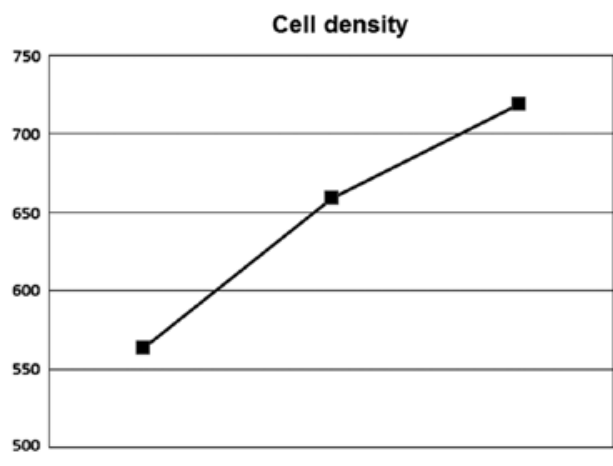

E-cadherin/ $\beta$-actin

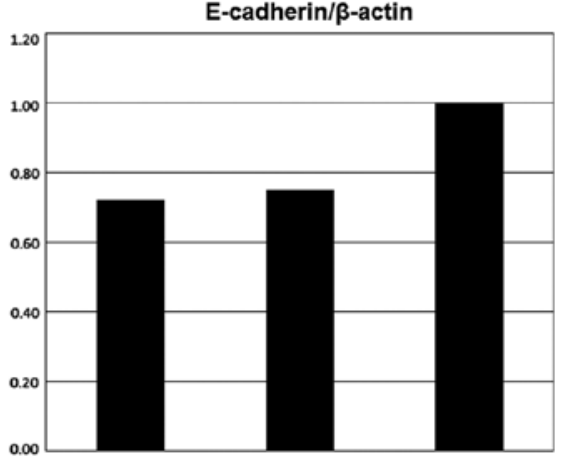

Figure 2. Expression of cellular proteins during cell proliferation. Expression of c-Met proteins decreased depending on time and increase in cell density (A). In contrast, expression of E-cadherin was increased (B). Protein bands were obtained from western blotting. 


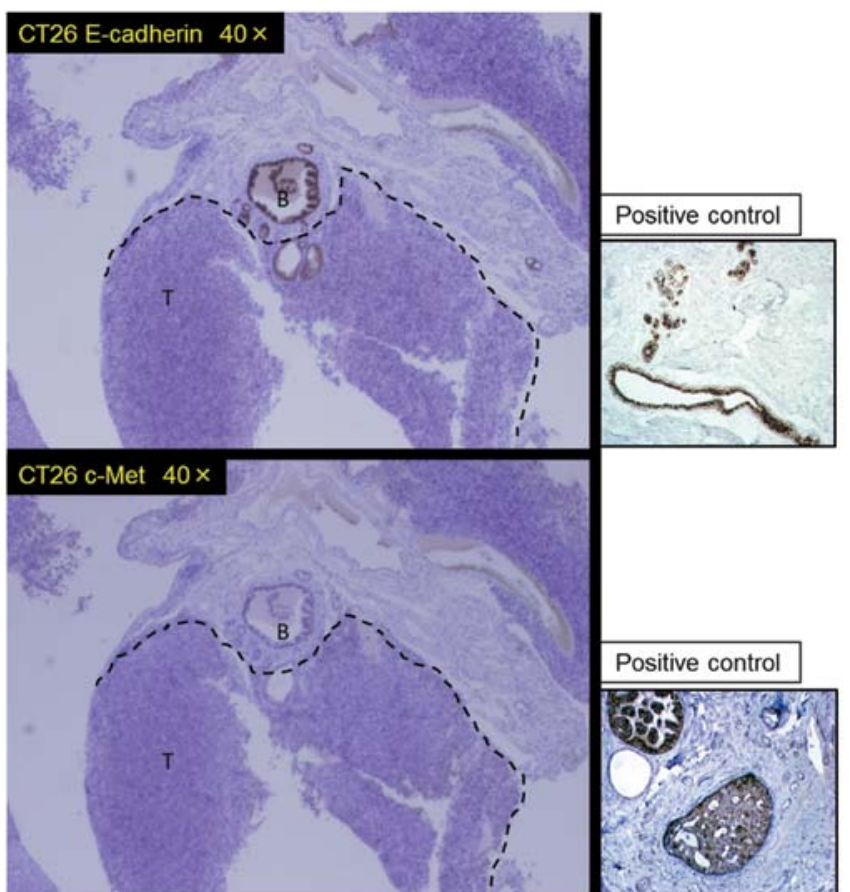

Figure 3. Immunohistochemical staining. Metastatic liver tumor was not stained by the c-Met antibody and E-cadherin antibody in the CT26 liver metastasis model. ' $\mathrm{T}$ ' indicates metastatic liver tumor and ' $\mathrm{B}$ ' indicates bile duct. Each positive control was obtained from human breast cancer.

With TGF- $\beta$, the peak was detected at $24 \mathrm{~h}$ and continued to $48 \mathrm{~h}$, and with HGF, the peak was detected at $24 \mathrm{~h}$ and slightly decreased at $48 \mathrm{~h}$. The increase in Slug expression was dimin- ished at $96 \mathrm{~h}$ for both TGF- $\beta$ and HGF. TGF- $\beta$ induced the activation of Smad2 at $30 \mathrm{~min}$, which continued to $90 \mathrm{~min}$, and Smad3, which peaked at $30 \mathrm{~min}$, despite no differences in the total amounts of Smad2/3, Smad4, and Smad7 present (data not shown). In contrast, HGF exerted no action on these factors, and c-Met knockdown had no effect on the TGF- $\beta$-induced cell signal pathway (data not shown).

We then examined the cellular signaling pathway induced by TGF- $\beta$ or HGF (Fig. 7A) and found that TGF- $\beta$ induced phosphorylation of ERK from 30 min with weak phosphorylation continuing to $90 \mathrm{~min}$, but no phosphorylation of Akt and JNK. HGF mediated phosphorylation of both ERK and Akt from $30 \mathrm{~min}$, which continued over $90 \mathrm{~min}$, but not JNK. Akt inhibitor blocked phosphorylation of Akt but had no effect on TGF- $\beta$-induced activation of ERK, Snail, and Slug. $\mathrm{U}-0126$, which is a MAPK kinase inhibitor, did not reduce Snail activity either by TGF- $\beta$ at a concentration that blocked ERK phosphorylation (Fig. 7B). In contrast, HGF-induced Slug activation was completely inhibited by both Akt inhibitor and U-0126 (Fig. 7C), and changes in E-cadherin and vimentin phosphorylation by HGF were also blocked by these inhibitors (data not shown).

Effect of chemotherapeutic agent on the EMT process. 5-Fluorouracil (5-FU), one of the most common and basic of chemotherapeutic agents, mediated cell death of the present CT26 cell line $\left(\mathrm{IC}_{50}: 4.87 \pm 0.61 \mu \mathrm{M}\right)$ for $72 \mathrm{~h}$. We evaluated the effects of 5-FU on EMT transcription factors (Fig. 8) and found that $1 \mu \mathrm{M}$ 5-FU increased expression of Snail, which peaked at $24 \mathrm{~h}$ and gradually decreased at $96 \mathrm{~h}$; Slug, which began at $24 \mathrm{~h}$ and clearly peaked at $48 \mathrm{~h}$; and vimentin, which increased at
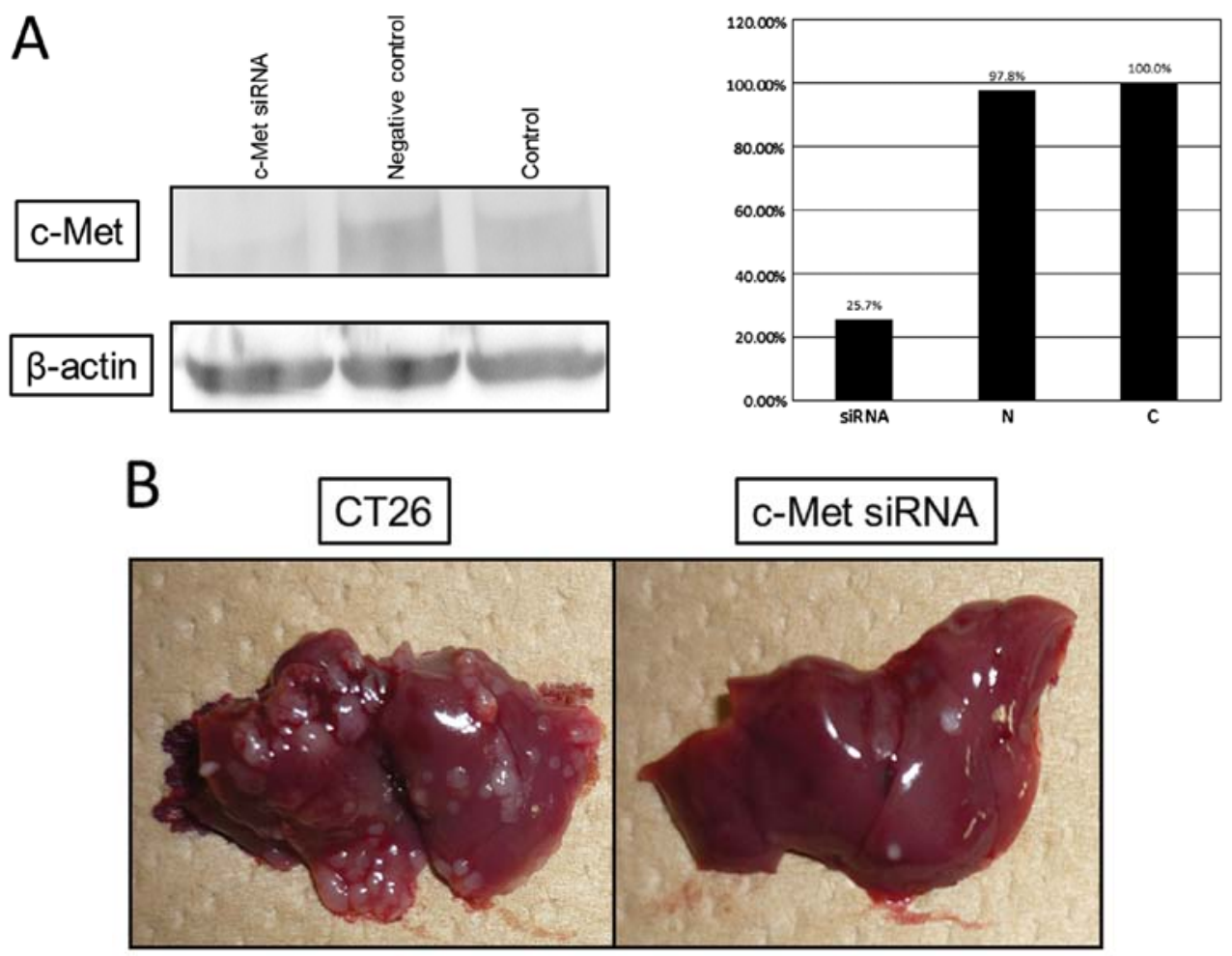

Figure 4. Effect of c-Met on liver metastasis. The protein of c-Met was knocked down to about $30 \%$ of the control value by siRNA (A). On the 21st day after injection of cancer cells in the spleen, numerous metastatic tumors were detected in the liver, but cancer cells in which c-Met expression was knocked down clearly resulted in fewer tumors (B). 
A

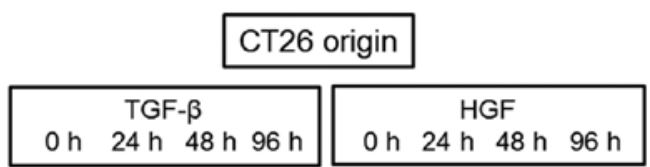

E-cadherin
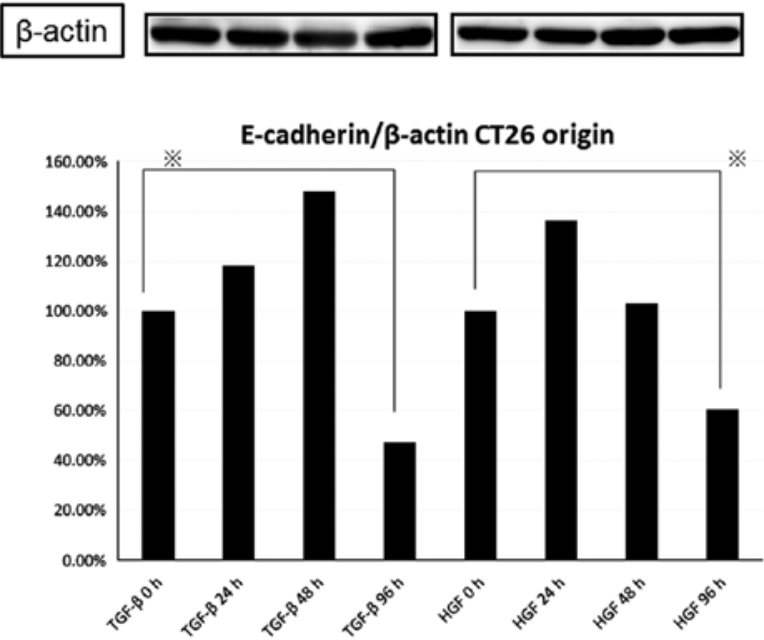

C CT26 origin

\begin{tabular}{|ll|}
\hline \multicolumn{1}{|c|}{ TGF- $\beta$} \\
$0 \mathrm{~h}$ & $24 \mathrm{~h} 48 \mathrm{~h} 96 \mathrm{~h}$ \\
\hline
\end{tabular}

\begin{tabular}{|c|c|}
\hline HGF \\
\hline $\mathrm{h} \quad 24 \mathrm{~h} \quad 48 \mathrm{~h} \quad 96 \mathrm{~h}$ \\
\hline
\end{tabular}
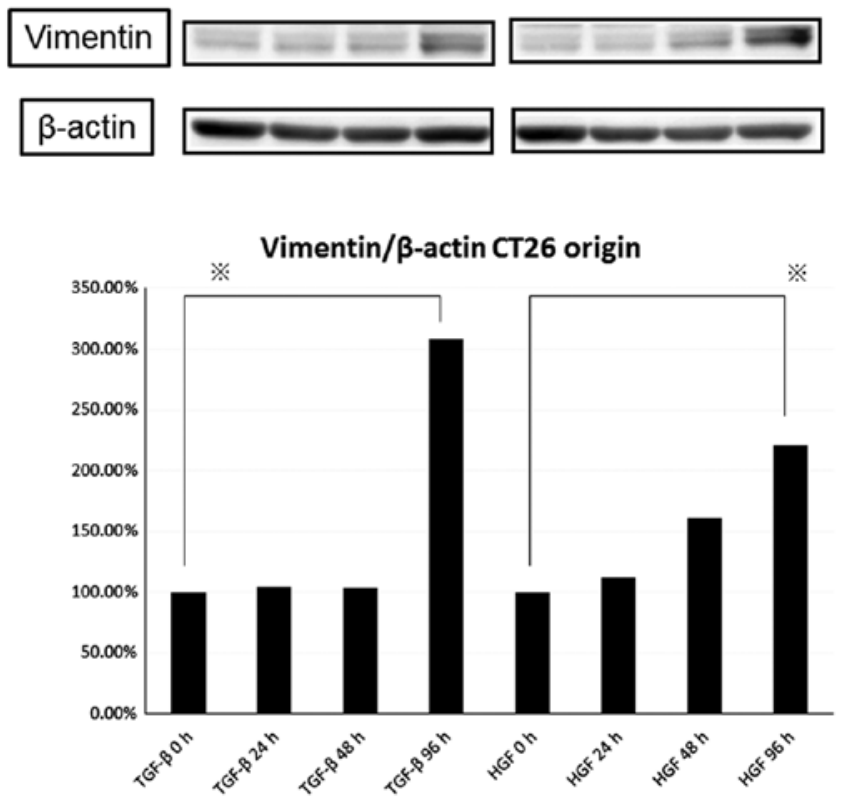

$24 \mathrm{~h}$ and continued to $96 \mathrm{~h}$. 5-FU phosphorylated ERK and Akt after $30 \mathrm{~min}$ but had no effect on Smad2/3. 5-FU also induced caspase- 3 activation at $24 \mathrm{~h}$ that peaked at $48 \mathrm{~h}$.

Finally, we studied the chemotherapeutic effect of 5-FU on cell death and signal transduction in the EMT process (Fig. 9). Pretreatment of CT26 cells with $5 \mathrm{ng} / \mathrm{ml}$ TGF- $\beta$ for 96 h enhanced 5-FU-induced cell death by $10 \%$, compared with the control, and $20 \mathrm{ng} / \mathrm{ml} \mathrm{HGF}$ also augmented the chemothera-
B
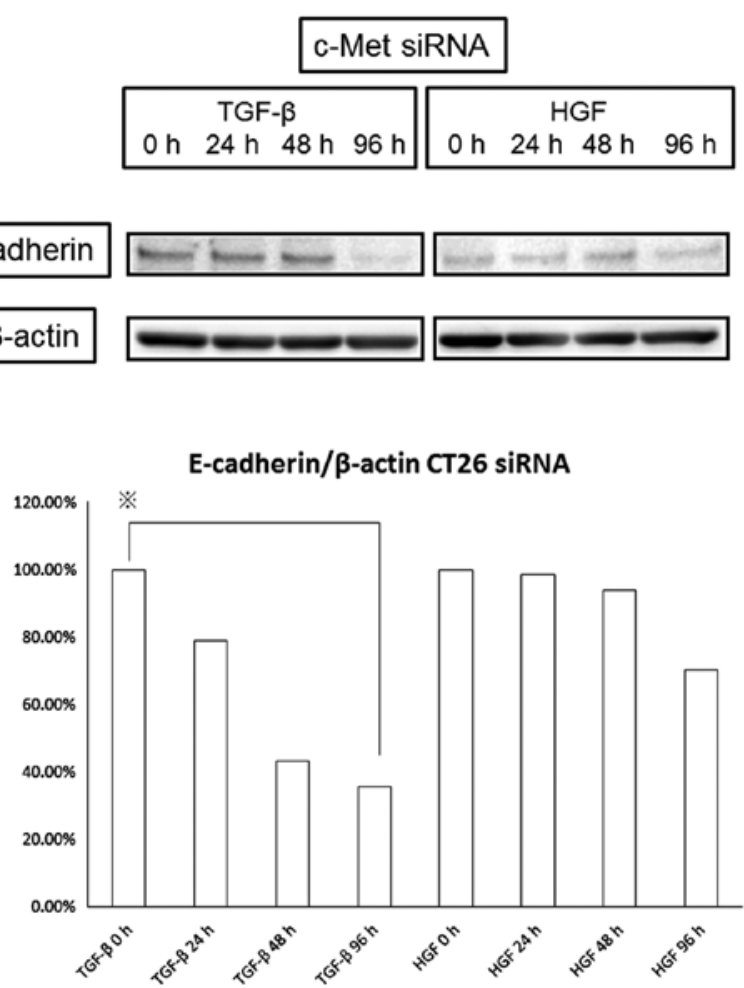

Figure 5. Expression of EMT-related proteins. (A), HGF $20 \mathrm{ng} / \mathrm{ml}$ reduced the level of E-cadherin as well as did TGF- $\beta 5 \mathrm{ng} / \mathrm{ml}$ in a time-dependent manner. (B), However, knockdown of c-Met diminished the HGF-induced decrease of E-cadherin expression. (C), HGF increased the expression of vimentin as well as TGF- $\beta$ in a time-dependent manner. ${ }^{*} \mathrm{p}<0.05$.

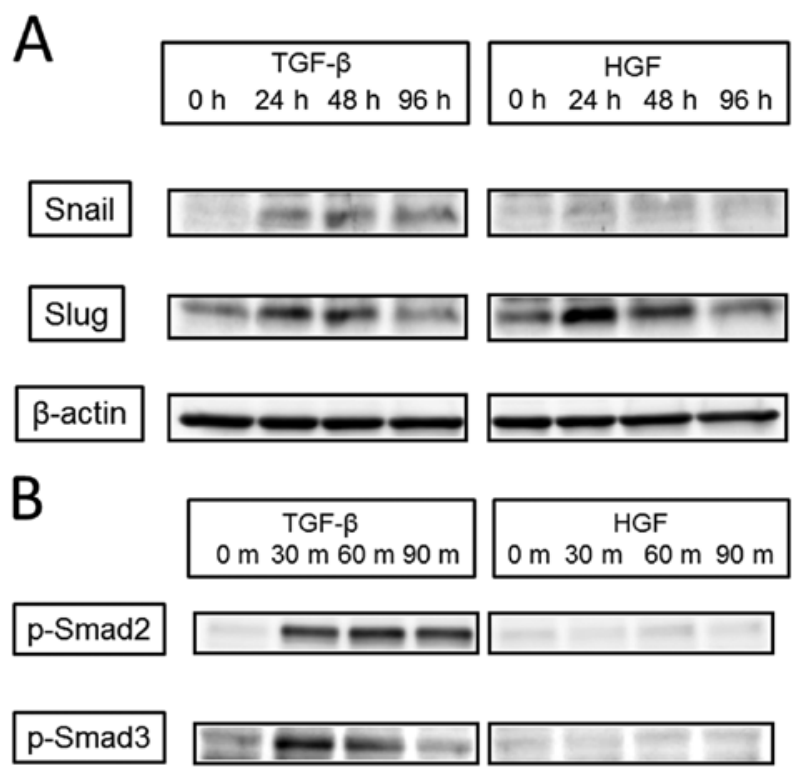

$\beta$-actin

Figure 6. Differences in the EMT signaling pathway between TGF- $\beta$ and HGF. (A, upper panel), Snail was detected by addition of TGF- $\beta$ starting from $24 \mathrm{~h}$, peaked at $48 \mathrm{~h}$, and continued to $96 \mathrm{~h}$, but was not detected at any time by addition of HGF. (A, lower panel), Slug was increased by both TGF- $\beta$ and HGF. With TGF- $\beta$, the peak was detected at $24 \mathrm{~h}$ and continued to $48 \mathrm{~h}$; with HGF, the peak was detected at $24 \mathrm{~h}$ with a slight decrease at $48 \mathrm{~h}$. (B), TGF- $\beta$ induced the activation of Smad2 for $30 \mathrm{~min}$, which continued to $90 \mathrm{~min}$, and Smad3, which peaked at $30 \mathrm{~min}$; however, no activation was induced by HGF. 


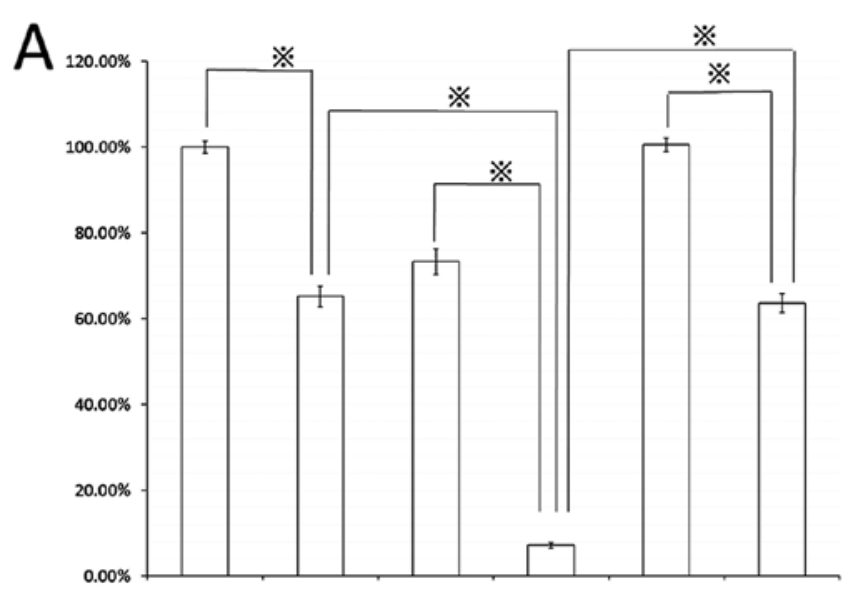

\begin{tabular}{|c|c|c|c|c|c|c|}
\hline $\begin{array}{c}\text { TGF- } \beta(5 \\
\mathrm{ng} / \mathrm{ml})\end{array}$ & - & - & + & + & - & - \\
\hline HGF $(20 \mathrm{ng} / \mathrm{ml})$ & - & - & - & - & + & + \\
\hline $5-\mathrm{FU}(30 \mathrm{mM})$ & - & + & - & + & - & + \\
\hline
\end{tabular}

B

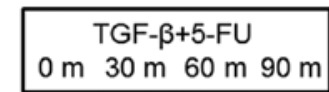

p-ERK

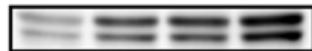

$\beta$-actin

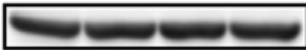

Figure 9. Chemotherapeutic effect of 5-FU on EMT-induced cells. (A), Pretreatment with $5 \mathrm{ng} / \mathrm{ml}$ TGF- $\beta$ enhanced 5 -FU-induced cell death by $10 \%$, and $20 \mathrm{ng} / \mathrm{ml} \mathrm{HGF}$ also augmented the chemotherapeutic effect of 5-FU by $63 \%$. (B), During EMT induced by both TGF- $\beta$ and HGF, 5 -FU induced stronger ERK phosphorylation than that in non-EMT-induced cells $\left({ }^{*} \mathrm{p}<0.05\right)$.

cell-cell adhesion (24). The present study found that with the decreased expression of c-Met, both cell density and E-cadherin increased. Vimentin, another commonly used molecular marker for EMT, is well known (25), and its increase with the loss of expression of E-cadherin by HGF described in the present study may be involved in EMT for colon cancer cells. HGF is also a major driver of cancer progression (26) and regulates regular signaling pathways, such as those of Akt or ERK, to promote carcinogenesis (27). Because TGF- $\beta$, one of the most essential inducers of EMT, is important in the progression of carcinoma to an invasive state (28), we evaluated differences in the signal pathway.

Among the molecular factors related to EMT induction, such as Snail, Slug, Twist, EF1/ZEB1, and SIP1/ZEB2 (21), Snail is a zinc finger transcription factor that induces EMT by directly repressing E-cadherin expression and confers epithelial cells with migratory and invasive properties as an important step for metastasis $(6,29)$. Slug, another zinc finger protein, is closely related to the Snail pathway and regulation of E-cadherin gene transcription (30). Furthermore, other cross-talk pathways have also been focused on (31), and the synergy between Ras signaling and Smad signaling was found to be critical in the induction of EMT. In fact, the receptor of TGF- $\beta$ is well known to activate MAPKs, such as ERK, JNK, and p38 MAP kinases, PI3 kinase, and small GTPases (31). The present study showed that ERK/Akt signaling, but not the Smad pathway, might be the main pathway in HGF-induced EMT, despite the fact that the Smad pathway, but not ERK/Akt, was critical for induction of EMT by TGF- $\beta$. The MAPK/Akt pathway is indispensable in HGF/c-Met signaling (32), and activated Akt was reported to induce loss of cell-cell adhesion, morphological changes, and induction of cell motility (33). Additionally, HGF-induced cell scattering or invasive action is abrogated due to down-regulation of phosphorylated Akt (10). In contrast, in the induction of EMT, TGF- $\beta$ cooperates with other signaling pathways, such as Wnt (34), Hedgehog (35), and Notch (36), which are all pathways linked to the stem cell renewal pathway (37). TGF- $\beta$ induced EMT or its repressors, such as Twist or Snail, also confer stem cell-like properties to non-carcinogenic, immortalized human mammary epithelial cells, providing the first link between EMT and 'stemness'. Indeed, the EMT process was found to generate stem-like properties in breast cancer cells (38). As a concept of cancer stemness, Snail includes not only stem cell-like properties but also resistance to chemo/radiation therapy under the self-renewal process (39). Namely, there is a possibility for cancer therapy through inhibition of EMT not only to reduce metastasis but also to improve drug sensitivity (40). Therefore, we are planning additional study of chemotherapeutic agents to evaluate a novel concept for therapeutic strategy.

Chemotherapeutic agents such as paclitaxel (41) or oxaliplatin (42) make cancer cells susceptible to EMT. The present study showed 5-FU to phosphorylate ERK/Akt and activate Snail and Slug, but not Smad, in an EMT-like manner. Because the ERK pathway has dual actions related to both cell proliferation and growth inhibition $(12,13,43)$, it is still unclear whether 5-FU-induced ERK activation itself is directly related with EMT. However, there is another possibility, that 5-FU produces reactive oxygen species (ROS) and that these ROS inhibit phosphatase action of cell signaling-related proteins to lead to phosphorylation of ERK accordingly $(11,12)$. ROS itself was shown to lead to EMT though the expression of Snail and to cause genomic instability and oxidative damage to DNA (44). Taken together, EMT was evaluated in relation to drug resistance of anticancer agents (41). However, the early response, but not the long-term reaction, to these agents is still unclear and controversial. Some reports showed high expression of E-cadherin to relate to higher chemosensitivity $(45,46)$, whereas its expression has also been related to lower chemosensitivity (47). Further, expression of E-cadherin does not correlate with the effect of chemotherapy or reflect patient prognosis (48). Commonly, loss or low expression of E-cadherin in liver metastasis occurs more frequently in CRC related to poor patient prognosis (49). In the present study, low expression of E-cadherin was detected in the EMT process and high chemosensitivity for 5-FU was shown. In the signalling pathway as well, ERK activation by 5-FU-increased more when EMT was present, indicating ROS expression to be higher. Although the connection between E-cadherin expression and drug-sensitivity in the present study was unclear, EMT and the signaling thereof were affected by different agents, TGF- $\beta$ and HGF. In particular, the ERK/Akt pathway might be critical in the process of HGF-induced EMT.

After hepatectomy for liver metastasis from CRC, serum HGF elevates for liver regeneration (50), but this does not increase the risk of new metastasis and aggressive tumor formation. As demonstrated in the present study, the reason 
was due to diminished c-Met expression at the metastatic site. Chemotherapeutic agents should be effective even if c-Met expression results in regeneration of cancer cells. However, long-term use of chemotherapeutic agents might induce drugresistant and distant metastases through the activation of the EMT-related signaling pathway. Further investigation will be necessary to determine therapeutic strategy with the use of anticancer agents.

\section{References}

1. Bingham S and Riboli E: Diet and cancer - the European prospective investigation into cancer and nutrition. Nat Rev Cancer 4: 206-215, 2004.

2. Benoist $\mathrm{S}$ and Nordlinger B: The role of preoperative chemotherapy in patients with resectable colorectal liver metastases. Ann Surg Oncol 16: 2385-2390, 2009.

3. Takeuchi H, Bilchik A, Saha S, et al: c-MET expression level in primary colon cancer: a predictor of tumor invasion and lymph node metastases. Clin Cancer Res 9: 1480-1488, 2003.

4. Matsui S, Osada S, Tomita $\mathrm{H}$, et al: Clinical significance of aggressive hepatectomy for colorectal liver metastasis, evaluated from the HGF/c-Met pathway. Int J Oncol 37: 289-297, 2010.

5. Bates RC and Mercurio AM: The epithelial-mesenchymal transition (EMT) and colorectal cancer progression. Cancer Biol Ther 4: 365-370, 2005.

6. Zavadil J and Bottinger EP: TGF-beta and epithelial-to-mesenchymal transitions. Oncogene 24: 5764-5774, 2005.

7. Derynck R and Zhang YE: Smad-dependent and Smad-independent pathways in TGF-beta family signalling. Nature 425: 577-584 2003.

8. Bierie B and Moses HL: Tumour microenvironment: TGFbeta: the molecular Jekyll and Hyde of cancer. Nat Rev Cancer 6: 506-520, 2006.

9. Zhang B, Halder SK, Zhang S and Datta PK: Targeting transforming growth factor-beta signaling in liver metastasis of colon cancer. Cancer Lett 277: 114-120, 2009.

10. Chang HY, Kao MC, Way TD, Ho CT and Fu E: Diosgenin suppresses hepatocyte growth factor (HGF)-induced epithelialmesenchymal transition by down-regulation of Mdm2 and vimentin. J Agric Food Chem 59: 5357-5363, 2011.

11. Osada S, Tomita H, Tanaka Y, et al: The utility of vitamin K3 (menadione) against pancreatic cancer. Anticancer Res 28: 45-50, 2008.

12. Osada S, Sakashita F, Hosono Y, et al: Extracellular signalregulated kinase phosphorylation due to menadione-induced arylation mediates growth inhibition of pancreas cancer cells Cancer Chemother Pharmacol 62: 315-320, 2008.

13. Osada S, Saji S and Osada K: Critical role of extracellular signalregulated kinase phosphorylation on menadione (vitamin K3) induced growth inhibition. Cancer 91: 1156-1165, 2001.

14. Osada S and Carr BI: Mechanism of novel vitamin K analog induced growth inhibition in human hepatoma cell line. J Hepatol 34: 676-682, 2001.

15. Osada S, Osada $\mathrm{K}$ and Carr BI: Tumor cell growth inhibition and extracellular signal-regulated kinase (ERK) phosphorylation by novel K vitamins. J Mol Biol 314: 765-772, 2001.

16. Osada S, Sakashita F, Katoh H, Sugiyama Y and Adachi Y: Identification of an immune tolerance reaction in response to pretreatment with frozen pancreatic tissue in islet cell transplantation in rats. Pancreas 30: e29-e33, 2005.

17. Osada S, Imai H, Tomita $\mathrm{H}$, et al: Vascular endothelial growth factor protects hepatoma cells against oxidative stress-induced cell death. J Gastroenterol Hepatol 21: 988-993, 2006.

18. Thiery JP: Epithelial-mesenchymal transitions in tumour progression. Nat Rev Cancer 2: 442-454, 2002.

19. Wilmanns C, Steinhauer S, Grossmann J and Ruf G: Site-dependent differences in clinical, pathohistological, and molecular parameters in metastatic colon cancer. Int J Biol Sci 5: 458-465, 2009.

20. Tsuji T, Ibaragi S, Shima K, et al: Epithelial-mesenchymal transition induced by growth suppressor p12CDK2-AP1 promotes tumor cell local invasion but suppresses distant colony growth Cancer Res 68: 10377-10386, 2008.

21. Lee JM, Dedhar S, Kalluri R and Thompson EW: The epithelialmesenchymal transition: new insights in signaling, development, and disease. J Cell Biol 172: 973-981, 2006.
22. Kang Y and Massague J: Epithelial-mesenchymal transitions: twist in development and metastasis. Cell 118: 277-279, 2004.

23. Wu Y and Zhou BP: New insights of epithelial-mesenchymal transition in cancer metastasis. Acta Biochim Biophys Sin 40: 643-650, 2008.

24. Xie LQ, Bian LJ, Li Z, Li Y, Li ZX and Li B: Altered expression of E-cadherin by hepatocyte growth factor and effect on the prognosis of nasopharyngeal carcinoma. Ann Surg Oncol 17: 1927-1936, 2010.

25. Walsh LA and Damjanovski S: IGF-1 increases invasive potential of MCF 7 breast cancer cells and induces activation of latent TGF-beta1 resulting in epithelial to mesenchymal transition. Cell Commun Signal 9: 10, 2011.

26. Ding W, You H, Dang H, et al: Epithelial-to-mesenchymal transition of murine liver tumor cells promotes invasion. Hepatology 52: 945-953, 2010

27. Ogunwobi OO and Liu C: Hepatocyte growth factor upregulation promotes carcinogenesis and epithelial-mesenchymal transition in hepatocellular carcinoma via Akt and COX-2 pathways. Clin Exp Metastasis 28: 721-731, 2011.

28. Nawshad A, Lagamba D, Polad A and Hay ED: Transforming growth factor-beta signaling during epithelial-mesenchymal transformation: implications for embryogenesis and tumor metastasis. Cells Tissues Organs 179: 11-23, 2005.

29. Peinado H, Olmeda D and Cano A: Snail, Zeb and bHLH factors in tumour progression: an alliance against the epithelial phenotype? Nat Rev Cancer 7: 415-428, 2007.

30. Pon YL, Zhou HY, Cheung AN, Ngan HY and Wong AS: p70 S6 kinase promotes epithelial to mesenchymal transition through snail induction in ovarian cancer cells. Cancer Res 68: 6524-6532, 2008.

31. Miyazono K: Transforming growth factor- $\beta$ signaling in epithelialmesenchymal transition and progression of cancer. Proc the Japan Academy, Series B 85: 314-323, 2009.

32. Trusolino L, Bertotti A and Comoglio PM: MET signalling: principles and functions in development, organ regeneration and cancer. Nat Rev Mol Cell Biol 11: 834-848, 2010.

33. Larue L and Bellacosa A: Epithelial-mesenchymal transition in development and cancer: role of phosphatidylinositol 3' kinase/ AKT pathways. Oncogene 24: 7443-7454, 2005.

34. Vincan $\mathrm{E}$ and Barker N: The upstream components of the Wnt signalling pathway in the dynamic EMT and MET associated with colorectal cancer progression. Clin Exp Metastasis 25: 657-663, 2008.

35. Karhadkar SS, Bova GS, Abdallah N, et al: Hedgehog signalling in prostate regeneration, neoplasia and metastasis. Nature 431: 707-712, 2004.

36. Wang Z, Banerjee S, Li Y, Rahman KM, Zhang Y and Sarkar FH: Down-regulation of notch-1 inhibits invasion by inactivation of nuclear factor-kappaB, vascular endothelial growth factor, and matrix metalloproteinase-9 in pancreatic cancer cells. Cancer Res 66: 2778-2784, 2006.

37. Fuxe J, Vincent T and Garcia de Herreros A: Transcriptional crosstalk between TGF-beta and stem cell pathways in tumor cell invasion: role of EMT promoting Smad complexes. Cell Cycle 9: 2363-2374, 2010

38. Creighton CJ, Chang JC and Rosen JM: Epithelial-mesenchymal transition (EMT) in tumor-initiating cells and its clinical implications in breast cancer. J Mammary Gland Biol Neoplasia 15: 253-260, 2010

39. Mani SA, Guo W, Liao MJ, et al: The epithelial-mesenchymal transition generates cells with properties of stem cells. Cell 133: 704-715, 2008.

40. Singh A and Settleman J: EMT, cancer stem cells and drug resistance: an emerging axis of evil in the war on cancer. Oncogene 29: 4741-4751, 2010.

41. Kajiyama H, Shibata K, Terauchi M, et al: Chemoresistance to paclitaxel induces epithelial-mesenchymal transition and enhances metastatic potential for epithelial ovarian carcinoma cells. Int J Oncol 31: 277-283, 2007.

42. Yang AD, Fan F, Camp ER, et al: Chronic oxaliplatin resistance induces epithelial-to-mesenchymal transition in colorectal cancer cell lines. Clin Cancer Res 12: 4147-4153, 2006.

43. Tanahashi T, Osada S, Imai H, et al: Signal transduction of vitamin K3 for pancreas cancer therapy. Oncol Rev 5: 57-60, 2010.

44. Radisky DC, Levy DD, Littlepage LE, et al: Raclb and reactive oxygen species mediate MMP-3-induced EMT and genomic instability. Nature 436: 123-127, 2005. 
45. Matsubara D, Ishikawa S, Oguni S, Aburatani H, Fukayama M and Niki T: Molecular predictors of sensitivity to the MET inhibitor PHA665752 in lung carcinoma cells. J Thorac Oncol 5: 1317-1324, 2010.

46. Koo JS, Jung W and Jeong J: The predictive role of E-cadherin and androgen receptor on in vitro chemosensitivity in triplenegative breast cancer. Jpn J Clin Oncol 39: 560-568, 2009.

47. Nakamura T, Kato Y, Fuji H, Horiuchi T, Chiba Y and Tanaka K: E-cadherin-dependent intercellular adhesion enhances chemoresistance. Int J Mol Med 12: 693-700, 2003.

48. Graziano F, Mandolesi A, Ruzzo A, et al: Predictive and prognostic role of E-cadherin protein expression in patients with advanced gastric carcinomas treated with palliative chemotherapy. Tumour Biol 25: 106-110, 2004.
49. Yu SJ, Yu JK, Ge WT, Hu HG, Yuan Y and Zheng S: SPARCL1, Shp2, MSH2, E-cadherin, p53, ADCY-2 and MAPK are prognosisrelated in colorectal cancer. World J Gastroenterol 17: 2028-2036, 2011.

50. Osada S, Kanematsu M, Imai $H$ and Goshima S: Clinical significance of serum HGF and c-Met expression in tumor tissue for evaluation of properties and treatment of hepatocellular carcinoma. Hepatogastroenterology 55: 544-549, 2008. 